\title{
Coronavirus Disease 2019 (COVID-19): review study
}

\author{
Abolfazl Jafari Sales ${ }^{1 *}$, Homeira Khaneshpour ${ }^{2}$, Mehrdad Pashazadeh ${ }^{3}$, Rozita Nasiri ${ }^{4}$
}

1. Department of Microbiology School of Basic Sciences, Kazerun Branch, Islamic Azad University, Kazerun, Iran

2. Department of Microbiology, Ahar Branch, Islamic Azad University, Ahar, Iran

3. Department of Immunology, Faculty of Medicine, Bursa Uludag University, Bursa, Turkey

4. Iran National Elite Foundation, Tehran, Iran

\section{Article Type:}

Review Article

\section{Article History:}

Received: 5 Jan 2020

Revised: 5 Feb 2020

Accepted: 29 Feb 2020

\section{*Correspondence:}

Abolfazl Jafari-Sales, Department of Microbiology, School of Basic Sciences, Kazerun Branch, Islamic Azad University, Kazerun, Iran. A.jafari_1392@yahoo.com

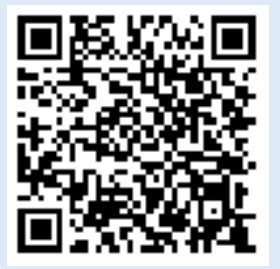

DOI: 10.29252/jorjanibiomedj.8.1.4

\begin{abstract}
On December 31, 2019, the Wuhan-China Health Commission reported a case of pneumonia in the city. The first symptoms began in mid-December 2019. Clinically isolated specimens identified the coronavirus as the cause of the disease. It was first shown as $2019-\mathrm{nCoV}$, and as the number of victims of the coronavirus crossed the border of thousands of people, the World Health Organization chose the official name COVID-19 for its illness. Although it appears to be of animal origin, it is rapidly transmitting from person to person around the world. The World Health Organization released a statement calling the outbreak of the new Corona virus a Public Health Emergency Situations that poses a threat to the whole world, not just China. In this study highlights how the virus is transmitted, the clinical signs, the laboratory characteristics, the pathogenicity of the virus, Vaccines, and the prevention and control of the spread of the virus.
\end{abstract}

Keywords: SARS-CoV, MERS-CoV, COVID-19, Pandemic

\section{Introduction}

Global health has been experiencing its third coronavirus crisis in less than twenty years. SARS-CoV emerged in 2002 as 8422 people were reportedly infected and 916 killed worldwide. Following MERS-CoV in 2012, 1401 were infected and 543 killed (1) and now nCoV (Wuhan), on December 31, 2019, the Wuhan Health Commission reported the outbreak of a mysterious new pneumonia in Wuhan City, which is progressing at a significant rate. As a result of research, it was concluded that Coronavirus is China (2). The virus was linked to a wholesale seafood and animal market in Wuhan, China (3). This prevalence of infections and epidemics over the past 20 years indicates that coronaviruses,

Copyright $\subseteq$ 2018, Jorjani Biomedicine Journal has published this work as an open access article under the terms of the Creative Commons Attribution License (http://creativecommons.org/licenses/by-nc/4.0/) which permits noncommercial uses of the work while it is properly cited. 
the situation is a threat to humanity, and it also affects the entire world economy (1). Coronaviruses were first identified in 1960 (4). Therefore, the cooperation of health workers, governments and all people is needed to prevent the spread of new coronavirus. The first sequence of the 2019$\mathrm{nCoV}$ genome was published online one day after approval by Zhang and other scientists at Fudan Shanghai University. Subsequently, on January 11, five more genomic sequences of the virus were placed on the GSAID database by various institutes across China, and allowing researchers around the world to begin research on the new coronavirus (3). Isolation and sequencing of the successful genomic sequence of Coronavirus 2019$\mathrm{nCoV}$ have been instrumental in understanding the origin of the virus and its infectious properties. However, there is still a lot of ambiguity and scientists are doing extensive research on this new virus. Following the outbreak of the virus, on January 30, 2020, the World Health Organization (WHO) issued a statement declaring the outbreak of new coronavirus to be the sixth leading cause of public health emergency worldwide, threatening not only China but all countries. On February 11, 2020, the WHO changed the name of the new coronavirus to COVID 19 (5). On the same day, the International Committee on Taxonomy of Viruses (Coronaviridae Study Group) named it SARS-CoV-2 (6-7). On March 11, the WHO upgraded the status of the COVID-19 outbreak from epidemic to pandemic. The clinical features and mortality from this virus have always been of interest to people, and it is also the focus of medical workers' research at present. However, given the numerous studies conducted in this case, it seems necessary to conduct a study to summarize the findings. The study was conducted to help health care workers in the country cope better with COVID 19. Based on the evidence and information in the studies, we can provide scientific and practical information on structure, transmission, clinical symptoms, Laboratory properties, Virus severity, vaccine, treatment, prevention and control.

\section{Virology}

Coronaviruses are a family of RNA viruses that contain Positive-sense single-stranded RNA (8). The virus belongs to the family Coronaviridae and to the subfamily Orthocoronavirinae. The coronavirus subfamily is genetically and serologically divided into four genera: Alphacoronavirus, Betacoronavirus, Deltacoronavirus and Gammacoronavirus (9). The diameter of this spherical virus is $70-120 \mathrm{~nm}$. RNA lengths range from 25.5 to $32 \mathrm{~kb}$ (10). Nearly four types of coronavirus have been identified in humans, mammals and birds. Human coronaviruses are caused by alpha and beta variants. Coronaviruses are one of the most prevalent viruses, with $30 \%$ to $60 \%$ of the Chinese population having antibodies against it (1). Approximately $80 \%$ of the $2019-\mathrm{nCoV}$ nucleotides are similar to the SARS-CoV nucleotides (10). Coronaviruses contain four types of proteins: 1) Spik Protein (S): are proteins that bind the virus to cell receptors and the virus enters the cell. 2) Membrane Protein (M): Causes virus germination. 3) Envelope Protein (E) causes the virus to germinate. 4) Nucleocapsid Protein $(\mathrm{N})$ : These proteins together with the genomic RNA form the nucleic capsid (8). Approximately $80 \%$ of the 2019-nCoV nucleotides are similar to the SARS-CoV nucleotides (10). Coronaviruses contain four types of proteins: 1) Spik Protein (S): are proteins that bind the virus to cell receptors and the virus enters the cell. 2) Membrane 
Protein (M): Causes virus germination. 3) Envelope Protein (E) causes the virus to germinate. 4) Nucleocapsid Protein $(\mathrm{N})$ : These proteins together with the genomic RNA form the nucleic capsid (8). In general, the coronavirus family comprises the two genera Toro virus and Corona virus, which are common in Ungulate and may cause diarrhea. The human coronavirus is antigenic in two strains of $22 \mathrm{qE}$ and DC43. The two strains, of course, also include animal source of the coronavirus (animals and rodents). Therefore, there is a cross-reaction between some human and animal strains (11). There is very little information on the pathogenicity of coronaviruses in humans. Known coronaviruses tend to resemble the gastrointestinal and gastrointestinal epithelial cells. Coronavirus infections are likely to spread to the host body like a mouse hepatitis virus. Coronaviruses cause respiratory, gastrointestinal, and neurological disorders (12). Viral infections usually affect the upper respiratory tract and affect only the lower respiratory tract in some people. The first and most common symptoms are fever, cough, and headache (1).

\section{How to transfer}

The virus was initially transmitted from animals to humans, but is now transmitting rapidly from human to human. As the origin of the disease is China, but through this human-to-human transmission has now reached other countries such as Germany, Iran, France, Thailand, Japan, South Korea, Vietnam, Canada, the United States and other countries (10). Suspected patients with coronavirus respiratory syndrome infection should be hospitalized in isolation units to prevent transmission (13). After the first outbreak, secondary cases were reported after approximately ten days. In addition, new patients had no contact with the seafood market and had only a history of contact with humans (14). Data on people under 18 years of age indicate that infection is relatively low in these individuals. The prevalence of infection in this age group is $2.4 \%$ (15). Often, human-to-human transmission occurs in close proximity to the infected person. Transmission is primarily that the infected person sneezes and that respiratory droplets, like the spread of influenza, can dissolve in the oral or nasal mucosa and lungs of people who inhaled the infected air (14). Huijun Chen and her colleagues found in a study of pregnant women who were in their last trimester of pregnancy that the COVID-19 virus did not transmit from mother to fetus. It should be noted, however, that this study was conducted in a small number of individuals (16).

\section{Clinical symptoms}

The duration of incubation and latency of the virus is about 1 to 14 days. This means that the person may be infected with the virus without symptoms, and have no knowledge of it $(17,18)$. Diarrhea is a symptom of with MERS-CoV and SARS-CoV but it is rarely seen in COVID-19. In a study of symptoms of COVID-19, chest pain, dizziness, and nausea were observed (19). Unilateral or bilateral involvement consistent with viral pneumonia was observed on X-rays or CT imaging of the studied patients (14). In a study of 41 hospitalized patients, pneumonia, shortness of breath, fever, symptoms of dry cough and fatigue were reported. Fewer cases of headache, hemoptysis, nausea and vomiting and diarrhea were also observed (17). Studies have found that side effects such as blood sugar, hypertension and cardiovascular disease were found in half of these patients. In addition, patients with abnormal dyspnea may indicate that these complications are likely to 
be important contributors to the death of COVID-19 patients (20).

\section{Laboratory properties}

In patients with COVID-19, the number of white blood cells can vary. In the early stages of infection, the number of lymphocytes and leukocytes appears to decrease, although lymphopenia is more common. Serum procalcitonin levels are also elevated in people with severe disease. With the onset of the disease, high D-dimer levels and severe lymphopenia have been reported to be equivalent to death (17).

\section{Virus severity}

The total death toll from the virus is less than $3 \%$. Hypertension, diabetes, and heart disease are factors that can impair the immune system that can make a patient vulnerable to illness, but 2019-nCoV appears to be less pathogenic than MERS-CoV and SARS-CoV (18). Coronaviruses are vulnerable to acidic $\mathrm{pH}$ and heat but appear to be more stable at $4^{\circ} \mathrm{C}$ (21). RNA-dependent RNA polymerase (RdRP) (RDR or RNA) is the replication of a protein enzyme present in RNA viruses that causes mutations to occur uninterruptedly (22). Studies have shown that SARS-CoV caused an increase in virus resistance in the 2002-2004 epidemic with genetic changes, reappearance and emergence of antigenic variants that were adapted to the host. The emergence of more resistant strains complicates and complicates treatment approaches. So we have to check if 2019nCoV behaves like SARS-CoV (18).

\section{Vaccines and treatment}

In general, there are few treatment options for viruses that suddenly cause disease. In parallel to this knowledge, there is no effective vaccine or treatment available today to prevent COVID-19. Laboratories are currently being tested for the treatment of COVID-19 using human SARS-CoV and human MERS-CoV data (14). Research shows that the 2019-nCoV E protein is very similar to the known coronavirus $\mathrm{E}$ protein. Thus the coronavirus vaccine affecting protein E could be a candidate for 2019-nCoV which requires animal models for vaccine development (10). According to recent studies by chloroquine phosphate researchers, an old drug used to treat malaria and have a significant effect on pneumonia has been suggested in a multi-center clinical trial in China as an effective drug for the prevention, diagnosis and treatment of COVID-19 pneumonia (23). There are currently no effective antiviral drugs. Inhalation of aerosol IFN- $\alpha$ or oral administration of Lopinavir / Ritonavir may help to improve the patient. Antibiotics should be avoided because antibiotics are used in bacterial infections (17). In this regard, a new study conducted in South Korea on a patient with COVID-19 has shown that taking Lopinavir / Ritonavir has significantly reduced the titer of the virus and improved the patient's condition (24). Remdesivir is an antiviral agent against Ebola and SARS viruses that has significant effects on the COVID-19 (25).

\section{Prevention and control}

As the disease has an incubation period, so asymptomatic carriers are a problem in eradicating the disease. These people can infect healthy people without understanding them. So, taking into account this issue, measures should be taken to prevent the infection of healthy people and the treatment of sick people (26). To eliminate the virus, a number of measures must be taken, such as timely dissemination of epidemic information to eliminate the source of infection, rapid 
diagnosis of the infected person, reporting, isolation of infected persons, support and physical and psychological protection to reduce stress and stress. The CDC recommends basic measures such as hand washing, use of disinfectants, avoiding contact with patients to prevent the spread of the virus. Based on the experience of SARS$\mathrm{CoV}$ in 2003, the Chinese government has taken many effective measures, including closing public transport, reducing migration and promoting personal protection with masks, hygiene and so on (14).

\section{Conclusion}

The emergence of SARS-CoV in 2002 and its prevalence in 32 countries and regions, then the prevalence of MERS-CoV and now 2019$\mathrm{nCoV}$, indicate that $\mathrm{CoVs}$ are periodically and unpredictably a clinical threat to the general population and health care personnel. Is becoming healthier around the world. COVID-19 is now rapidly expanding worldwide, affecting approximately 25 countries from 5 continents. Knowledge about the disease is currently limited. But what we can do now is take some basic measures to prevent it and control and treat the virus. As the knowledge of the virus grows, it will be possible to deal with it even better. So we hope that with the efforts of medical professionals and researchers, we will take significant steps to prevent public health from being compromised. In addition to the dangers of public health, the economies of many countries today are directly and indirectly affected. It is hoped that the virus can be defeated in the near future by preventing and cutting off the chain of outbreaks as well as appropriate remedies and discovering the vaccine and the effective drug.

\section{References}

1. Li G, Fan Y, Lai Y, Han T, Li Z, Zhou P, et al. Coronavirus infections and immune responses. Journal of Medical Virology. 2020;92(4):424-32. [DOI:10.1002/jmv.25685]

2. David JK, Salvatore R. Fear of the novel coronavirus. The Journal of Infection in Developing Countries. 2020;14(01). [DOI:10.3855/jidc.12496]

3. Zhu N, Zhang D, Wang W, Li X, Yang B, Song $\mathrm{J}$, et al. A Novel Coronavirus from Patients with Pneumonia in China, 2019. The New England journal of medicine. 2020;382(8):727-33. [DOI:10.1056/NEJMoa2001017]

4. Vahdat K, Amini A, Najafi A, Haerinejad MJ. A Review of Novel Coronavirus, cause of Middle East Respiratory Syndrome. Iranian South Medical Journal. 2014;16(6):486-92.

5. Lai CC, Shih TP, Ko WC, et al. Severe Acute Respiratory Syndrome Coronavirus 2(SARS Cov2) And Corona Virus Disease-2019(COVID-19): The Epidemic And The Challenges. Int $\mathrm{J}$ Antimicrob Agents (In press)2020; 105924 [DOI:10.1016/j.ijantimicag.2020.105924]

6. Gorbalenya AE. Severe acute respiratory syndrome-related coronavirus-The species and its viruses, a statement of the Coronavirus Study Group. BioRxiv. 2020.

7. National Health Commission's briefing on the pneumonia epidemic situation. Released on 23 Feb 2020.

8. Masters PS. Coronavirus genomic RNA packaging. Virology. 2019;537:198-207. [DOI:10.1016/j.virol.2019.08.031]

9. Chen Y, Guo Y, Pan Y, Zhao ZJ. Structure analysis of the receptor binding of 2019-nCoV. Biochemical and Biophysical Research Communications. 2020;in press ( https://doi.org/10.1016/j.bbrc.2020.02.071 [DOI:10.1016/j.bbrc.2020.02.071).] 
10. Ralph R, Lew J, Zeng T, Francis M, Xue B, Roux M, et al. 2019-nCoV (Wuhan virus), a novel Coronavirus: human-to-human transmission, travel-related cases, and vaccine readiness. Journal of infection in developing countries. 2020;14(1):3-17. [DOI:10.3855/jidc.12425]

11. Ghanei M., Karami A., Hosseinidost S. R., Abolghasemi H., Hosseini S. M. J. Severe acute respiratory syndrome(Sars). Journal of Military Medicine. 2003;4(4):265-72.

12. Ksiazek TG, Erdman D, Goldsmith CS, Zaki SR, Peret T, Emery S, et al. A novel coronavirus associated with severe acute respiratory syndrome. The New England journal of medicine. 2003;348(20):1953-66.

[DOI:10.1056/NEJMoa030781]

13. Bleibtreu A, Jaureguiberry S, Houhou N, Boutolleau D, Guillot H, Vallois D, et al. Clinical management of respiratory syndrome in patients hospitalized for suspected Middle East respiratory syndrome coronavirus infection in the Paris area from 2013 to 2016. BMC Infectious Diseases. 2018;18(1):331. [DOI:10.1186/s12879-018-32235]

14. Riza S, ErdoganAysegul, AgaogluPelin M, DineriYeliz, Yusuf C, SenelMahmut E, et al. 2019 Novel Coronavirus (COVID-19) Outbreak: A Review of the Current Literature. EJMO. 2020;4(1):1-7.

15. Report of the WHO-China Joint Mission on Coronavirus Disease 2019 (COVID-19) 16-24 February 2020.

16. Chen H, Guo J, Wang C, Luo F, Yu X, Zhang $\mathrm{W}$, et al. Clinical characteristics and intrauterine vertical transmission potential of COVID-19 infection in nine pregnant women: a retrospective review of medical records. The Lancet. 2020;6736(20):30360-3. [DOI:10.1016/S01406736(20)30360-3]

17. Deng S, Peng H-J. Characteristics of and Public Health Responses to the Coronavirus Disease 2019 Outbreak in China. Journal of

\section{Clinical Medicine. 2020;9(2):575. [DOI:10.3390/jcm9020575]}

18. Chen J. Pathogenicity and transmissibility of 2019-nCoV-A quick overview and comparison with other emerging viruses. Microbes and Infection. 2020;in press ( https://doi.org/10.1016/j.micinf.2020.01.004 [DOI:10.1016/j.micinf.2020.01.004).]

19. Chen N, Zhou M, Dong X, Qu J, Gong F, Han $\mathrm{Y}$, et al. Epidemiological and clinical characteristics of 99 cases of 2019 novel coronavirus pneumonia in Wuhan, China: a descriptive study. Lancet (London, England). 2020;395(10223):507-13. [DOI:10.1016/S01406736(20)30211-7]

20. Huang C, Wang Y, Li X, Ren L, Zhao J, Hu $\mathrm{Y}$, et al. Clinical features of patients infected with 2019 novel coronavirus in Wuhan, China. Lancet (London, England). 2020;395(10223):497-506. [DOI:10.1016/S0140-6736(20)30183-5]

21. Chang L, Yan Y, Wang L. Coronavirus Disease 2019: Coronaviruses and Blood Safety. Transfusion Medicine Reviews. 2020;in press( https://doi.org/10.1016/j.tmrv.2020.02.003 [DOI:10.1016/j.tmrv.2020.02.003).]

22. Cui J, Li F, Shi Z-L. Origin and evolution of pathogenic coronaviruses. Nature Reviews Microbiology. 2019;17(3):181-92. [DOI:10.1038/s41579-018-0118-9]

23. Gao J, Tian Z, Yang X. Breakthrough: Chloroquine phosphate has shown apparent efficacy in treatment of COVID-19 associated pneumonia in clinical studies. Bioscience trends. 2020; in press(DIO: $\quad 10.5582 /$ bst.2020.01047. [DOI:10.5582/bst.2020.01047]

24. Lim J, Jeon S, Shin HY, et al. Case Of The Index Patient Who Caused Tertiary Transmission Of Coronavirus Disease 2019 In Korea: The Application Of Lopinavir/Ritonavir For The Treatment Of COVID-19 Pneumonia Monitored By Quantitative RT-PCR. J Korean Med Sci 2020; 35(6): e79. [DOI:10.3346/jkms.2020.35.e79] 
25. Mulangu S, Dodd LE, Davey Jr RT, et al. A Randomized, Controlled Trial Of Ebola Virus Disease Therapeutics. New Engl J Med 2019; 381(24):

2293-303.
26. Wang F-S, Zhang C. What to do next to control the 2019-nCoV epidemic? The Lancet. 2020;395(10222):391-3. [DOI:10.1016/S01406736(20)30300-7]

\section{[DOI:10.1056/NEJMoa1910993]}

\section{How to cite:}

Jafari Sales A, Khaneshpour H, Pashazadeh M, Nasiri R. Coronavirus Disease 2019 (COVID-19): review study. Jorjani Biomedicine Journal. 2020; 8(1): 4-10. 